\title{
Desorption and Diffusion Characteristics within Bituminous in the Presence of Moisture
}

\author{
Zhongping Cui \\ Jinzhong Coal Planning and Design Institution,Yuci, Shanxi 030600,P.R. China \\ email: 460637881@qq.com
}

\begin{abstract}
Keywords: Desorption, Diffusion, Moisture, Methane.
Abstract. In order to investigate the effect of moisture on methane desorption and diffusion characteristics, a series of experimental measurements were performed on coal samples with different moisture contents. The experimental data was fitted and the mechanism that accounts for the reduction in desorption amount was analyzed. The result shows that the capacity of gas desorption in coal mass dramatically decreases due to the effect of water. Both the gas desorption amount, and the initial desorption rate decrease with the rise of moisture content. The result can provide guidance for reducing the risk of outburst by coal seam injection.
\end{abstract}

\section{Introduction}

The recovery of gas from natural unconventional deposits, such as the coal bed methane (CBM) and shale gas, is attracting growing interest all over the world and has led to increased efforts in studying the gas adsorption-desorption behavior of coal and organic-rich shales[1-4]. Actually, methane desorption property is the dominant role for the CBM production. Most of the gas is adsorbed, only a small part is free [5]. Main factors affecting coal gas desorption and diffusion consist of the moisture content of the desorption temperature, gas pressure, the coal particle size, coal metamorphic grade, coal failure types and geological structure, pore stress etc. Since the in situ coalbed is normally saturated by water, the effect of moisture on gas-coal interactions such as gas sorption, desorption, coal swelling and gas flow should be taken into account. The presence of water in the form of coal can be divided into free water and combined water[6-8], free water is the capillary adsorption or attached to the surface of the water inside coal, combined water is combined form in the presence of water with the mineral components. Studies on gas diffusion in coal normally indicate that the desorption rate or diffusivity decreases in the presence of moisture[9-11].

This study focuses on the influence of moisture on desorption and diffusion behavior in coal during methane desorption process. Two coal samples with different rank were selected and samples with different moisture contents were prepared for use. Subsequently, the experimental data obtained was fitted and the influence of moisture on diffusion is analyzed.

\section{The mathematical model of diffusion}

According to the Fick's second law of diffusion, combined with the experiments, it needs to do the following assumptions: $\square$ Coal particle is spherical particles; $\square$ The coal particles is isotropic homogeneous body; $\square$ The physical deformation does not exist in the coal particle gas adsorption process; $\square$ In the coal particles, gas flow process follow continuity and multi stage principle and law of conservation of mass. The mathematical model of diffusion of coal gas is expressed as [12-14]:

$$
\frac{Q_{t}}{Q_{\infty}}=1-\frac{6}{\pi^{2}} \sum_{n=1}^{\infty} \frac{1}{n^{2}} \exp \left(\frac{-D n^{2} \pi^{2} t}{r_{0}^{2}}\right)
$$

Where $Q_{t}, Q_{\infty}$ are separately the cumulative coal gas diffusion quantity at time $t$ and the gas 
diffusion quantity limit when time $t \rightarrow \infty, \mathrm{D}$ is the diffusion coefficient, $r_{0}$ is the coal radius, $t$ is the desorption time.

The desorption rate is the physical quantity describing sample desorption effect (the cumulative desorption rate from the desorption beginning to the time $t$ in the desorption process), it can be calculated by the follow form:

$$
\eta=\frac{Q_{t}}{Q_{\infty}}
$$

Where $\eta$ is the desorption rate.

When the desorption time $t$ is smaller $(<600 \mathrm{~s})$, Eq. (1) can be simplified as follow:

$$
\begin{aligned}
& \frac{Q_{t}}{Q_{\infty}}=\frac{6}{r_{0}} \sqrt{\frac{D t}{\pi}} \\
& k=\frac{6}{r_{0}} \sqrt{\frac{D}{\pi}}, \text { then Eq. (3) becomes } \\
& \frac{Q_{t}}{Q_{\infty}}=k \sqrt{t}
\end{aligned}
$$

\section{Experiment Section}

\section{Sample Collection}

Coal samples are collected from the Zhaozhuang Coal Mine, and Pingdingshan Coal Mine. Through analysis, the former is lean coal, and the other is coking coal. The two coals collected are prepared to $60-80$ mesh samples, and the samples particle size is $0.178 \sim 0.25 \mathrm{~mm}$. Its average particle size of 0.214 is used for the experiment. The samples were put into the drying oven under vacuum at $80 \square$, for 8 hours. Then the coal samples were reserved in the jar for use. The lean coal is numbered

\begin{tabular}{|c|c|c|c|c|c|c|}
\hline Sampling position & $\begin{array}{c}\text { Number of } \\
\text { samples }\end{array}$ & $\begin{array}{c}\text { Moisture } \\
(\%)\end{array}$ & $\begin{array}{c}\text { Volatiles } \\
(\%)\end{array}$ & $\begin{array}{l}\text { Ash } \\
(\%)\end{array}$ & $\begin{array}{c}\text { Fixed } \\
\text { carbon }(\%)\end{array}$ & Coal type \\
\hline Zhaozhuang Mine & $\# 1$ & 0.66 & 12.95 & 13.01 & 79.1 & Lean coal \\
\hline Pingdingshan Mine & $\# 2$ & 1.03 & 18.84 & 19.04 & 73.96 & $\begin{array}{c}\text { Coking } \\
\text { coal }\end{array}$ \\
\hline
\end{tabular}
as \#1, and the coking coal is numbered as \#2. Finally, the industrial analysis was conducted for the two coal samples, as shown in Table 1.

Table 1 Industrial analysis of coal samples

\section{Adsorption and desorption experiment}

Coal samples with different moisture contents were prepared according to the method described in ASTM D1412-04. The experimental system consists of 6 parts, including vacuum unit, inflation unit, temperature-control unit, date acquisition and processing unit, adsorption and desorption unit and gas collection unit. The system is shown in literature [6].

The whole experimental process can be simply summarized as: the thermostat is set at $30 \square$, after the free space volume determination, the experimental system connects to the vacuum pump and was vacuumed for 2 hours. Then the methane gas was expanded. The coal samples with different moisture content adsorb methane gas for at least 12 hours to reach the adsorption equilibrium 
pressure. When desorption begins, the desorption process needs $10 \mathrm{~h}$ until the cumulative gas desorption basically never changes over time (desorption amount is less than $0.01 \mathrm{~mL} / \mathrm{g}$ within $1 \mathrm{~h}$ ), which indicates the end of the adsorption and desorption experiment.

\section{Results and Discussion}

\section{Effect of water on gas desorption}

When the adsorption balance pressure is $0.45 \mathrm{MPa}$, the change of the cumulative gas desorption quantity of coal samples with different moisture contents as a function of time is shown in Fig. 1.

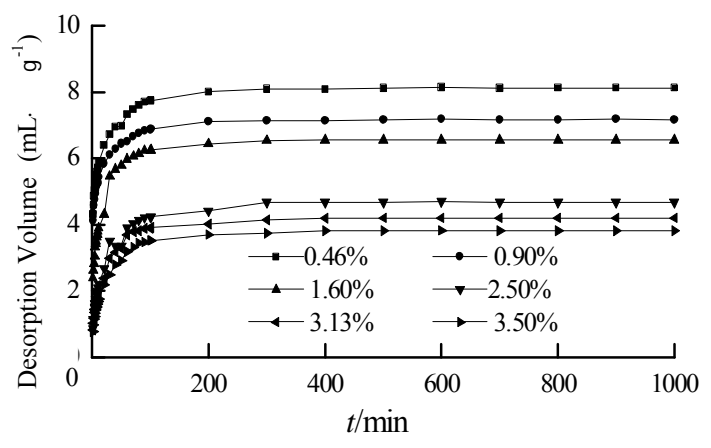

(a)Sample \#1

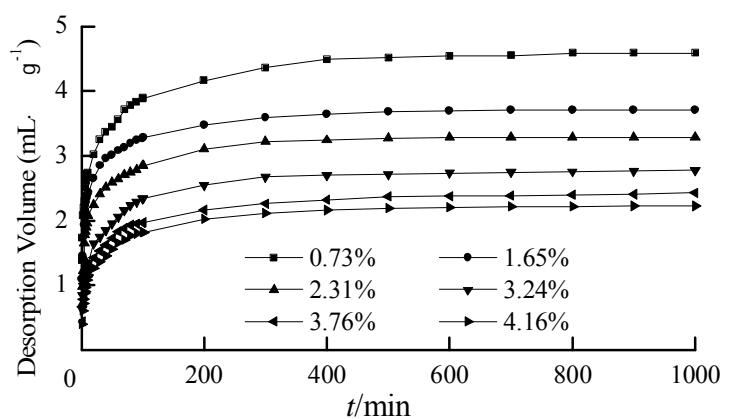

(b) Sample \#2

Fig. 1 Gas desorption curve under $0.45 \mathrm{MPa}$

\section{Effect of water on the initial desorption rate of gas}

According to the Fig. 1, the gas desorption rate of different moisture content can be obtained through the process of desorption data. The fitting results are shown in Fig. 2. It is not difficult to see that the moisture content of the coal samples in 10 minutes is higher than $35 \%$, illustrating the high desorption speed in the early stage of gas desorption. A large amount of methane is released into excavation space in short time. Thus, the initial desorption rate is an important factors affecting coal and gas outburst. The existence of water can effectively reduce the initial desorption rate of gas. Fig. 3 shows the relationship between the initial desorption rate and moisture content. It is observed that with the increase of moisture content, the initial desorption rate of sample $\# 1$ reduces from $70.87 \%$ to $34.54 \%$, reducing by $36.33 \%$; the sample \#2 decreases from $58.14 \%$ to $37.16 \%$, diminishing by $20.98 \%$. This means the moisture content significantly affects the initial gas desorption. The more moisture content is, the lower the gas desorption. The presence of moisture content can efficiently reduce the gas desorption, which provides guidance for reducing the danger of outburst by coal seam water injection.

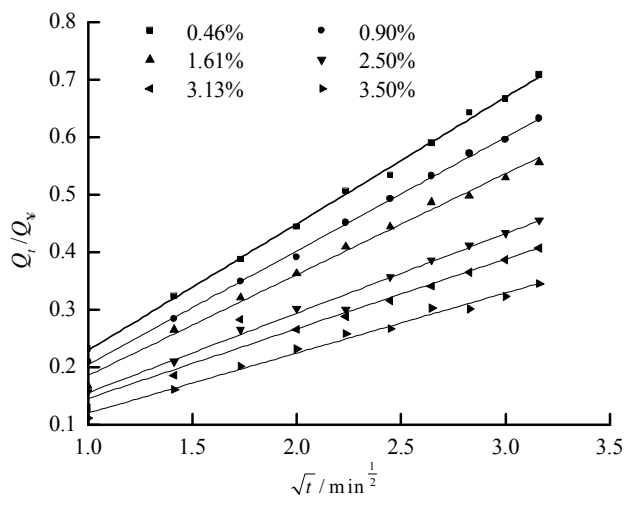

Sample \#1

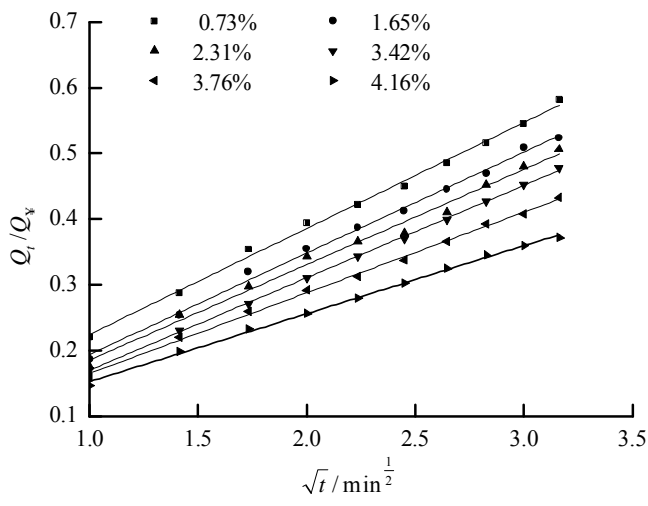

Sample \#2

Fig. 2 Relationship between desorption rate and $\sqrt{t}$ of tests in the first 10 min under 0.45 


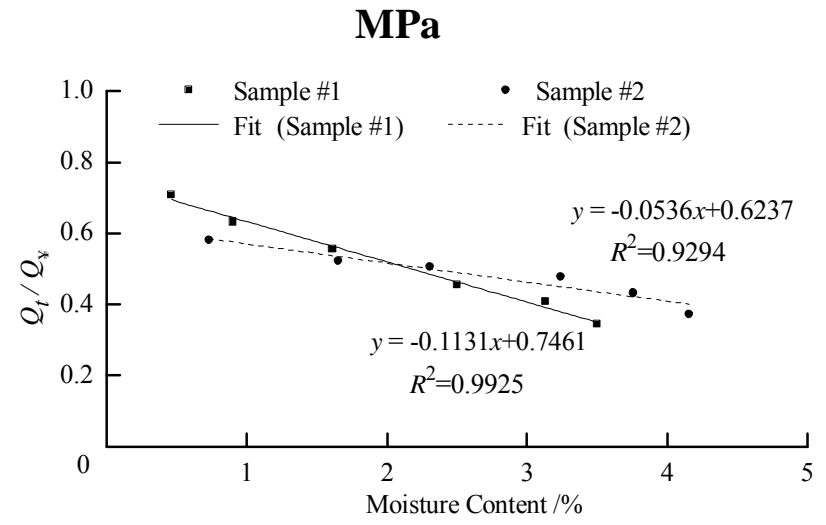

Fig. 3 Relationship between initial desorption rate and moisture content

\section{Conclusions}

1) The regularity of methane desorption and diffusion in coal samples with different moisture contents was investigated. The results show that the more coal moisture content is, the smaller the methane desorption quantity and the initial desorption rate. At the $0.45 \mathrm{MPa}$ equilibrium pressure, as the moisture content in sample $1 \#$ increases from $0.46 \%$ to $3.5 \%$, the initial desorption rate will reduce from $70.87 \%$ to $34.54 \%$, reducing by $36.33 \%$.

2) Affected by water, the motion of methane molecules is hindered, leading to the reduction in the desorption amount, desorption speed and desorption rate.

\section{Reference}

[1] M. Gasparik, A. Ghanizadeh, P. Bertier, et al. High-pressure methane sorption isotherms of black shales from the Netherlands, Energy \& Fuels 26 (2012) 4995-5004.

[2] D.Y. Li, Q.F. Liu, P. Weniger, et al. High-pressure sorption isotherms and sorption kinetics of $\mathrm{CH}_{4}$ and $\mathrm{CO}_{2}$ on coals, Fuel 89 (2010), 569-580.

[3] Y. Gensterblum, A. Merkel, A. Busch, et al. High-pressure $\mathrm{CH}_{4}$ and $\mathrm{CO}_{2}$ sorption isotherms as a function of coal maturity and the influence of moisture, Int. J. Coal Geol. 118(2013) 45-57.

[4] K. Wang, J. Zang, Y.F. Feng, et al. Effects of moisture on diffusion kinetics in Chinese coals during methane desorption, J. Nat. Gas Sci. Eng. 21(2014), 1005-1014.

[5] S. Harpalani, R.A. Schraufnagel. Shrinkage of coal matrix with release of gas and its impact onpermeability of coal, Fuel, 69 (1991) 551-556.

[6] B.S. Nie, T. Yang, X.C. Li, et al. Research on diffusion of methane in coal particles, Journal of China University of Mining \& Technology, 42 (2013) 975-981.

[7] C.R. Claskson, B.M. Bustin. Binary gas adsorption/desorption isotherms: effect of moisture and coal composition upon carbon dioxide selectivity over methane, Int. J. Coal Geol. 42(2000) 241-271.

[8] K.C. Xie. Coal structure and its reactivity. Beijing: Science Press, 2002,43-57.

[9] A. Busch, Y. Gensterblum, B.M. Krooss, et al. Methane and carbon dioxide Adsorption diffusion experiments on coal: upscaling and modeling. Int. J. Coal Geol. 60(2004) 151-168.

[10] M. Gruszkiewicz, M. Naney, J. Blencoe,et al. Adsorption kinetics of $\mathrm{CO}_{2}, \mathrm{CH}_{4}$, and their equimolar mixture on coal from the Black Warrior Basin, West-Central Alabama. Int. J. Coal Geol. 77(2009) 23-33.

[11] Z. Pan, L.D. Connell, M. Camilleri, et al, Effects of matrix moisture on gas diffusion and flow in coal. Fuel 89(2010) 3207-3217. 
[12] G.H. Ni, B.Q. Lin, C. Zhai, at el. Kinetic characteristics of coal gas desorption based on the pulsating injection, International Journal of Mining Science and Technology, 24(2014) 631-636.

[13] J. Crank. The Mathematics of Diffusion[M]. Oxford: Oxford University Press, 1979.

[14] E.D. Thimons, N. Kissellf. Diffusion of methane through coal. Fuel,1973 ,52(4) 274-280. 